
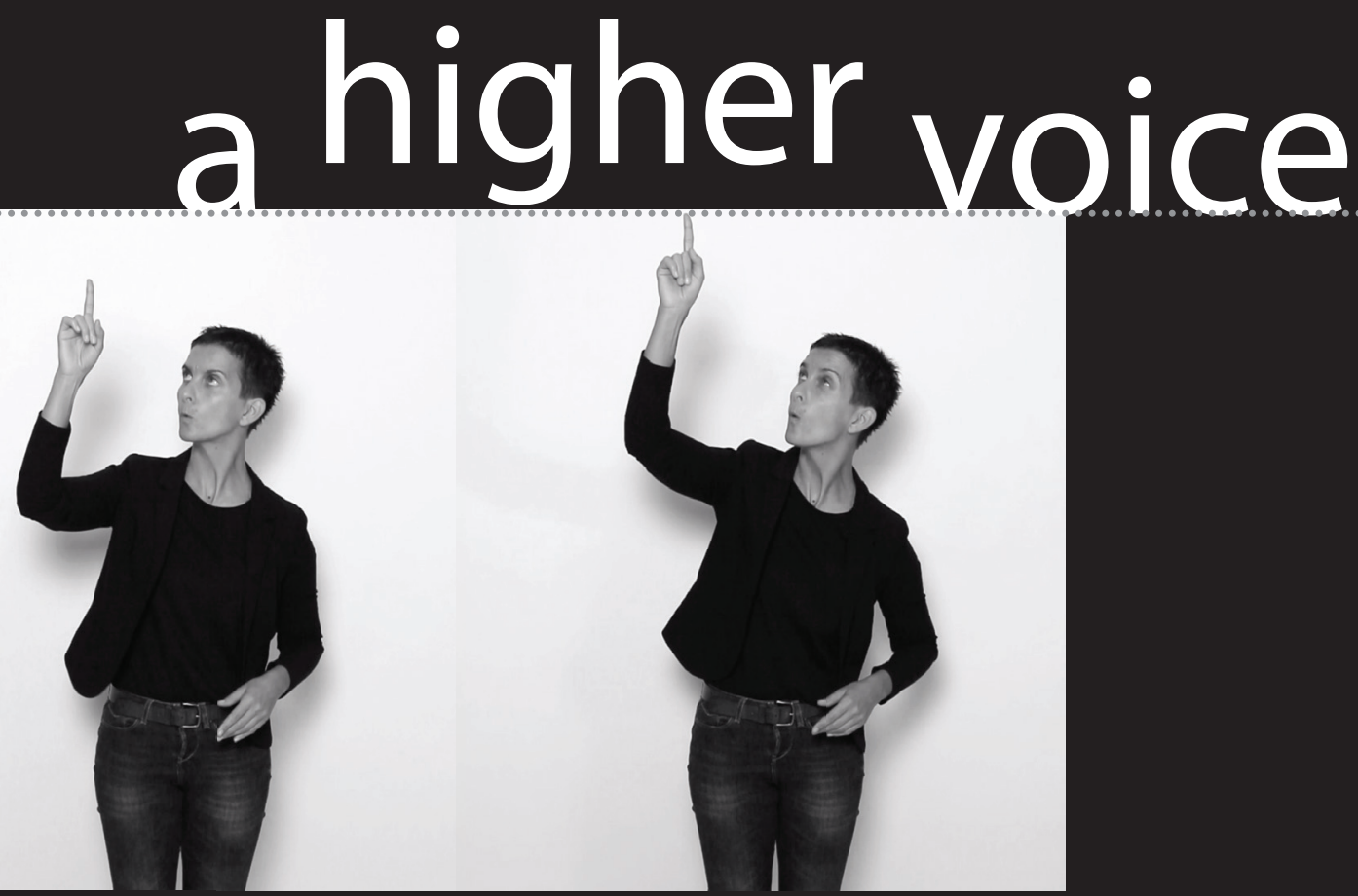


\section{A preliminary study exploring the relation between visual prosody and the prosodic components in sign language}

Maarten Renckens ${ }^{1}$

Leo De Raeve ${ }^{2,3}$

Erik Nuyts ${ }^{1}$

María Pérez Mena'

Ann Bessemans ${ }^{1}$

1 Hasselt University in

collaboration with PXL University College, Belgium;

2 Independent Information Centre about Cochlear Implantation (ONICI) Zonhoven, Belgium; 3 KIDS (Royal Institute for the Deaf) Hasselt, Belgium.

Type enriched with visual prosody is a powerful tool to encourage expressive reading. Visual prosody adds cues to text to guide vocal variations in loudness, duration, and pitch. More vocal variations result in a less monotonous voice and thus more expression. A positive effect of visual prosody is known on the voice of normal hearing readers and of signed bilingual deaf readers who developed signed language and spoken language. These deaf readers rely on speech as well as sign language and both modalities can be used interchangeably to compensate each other.

This preliminary study explores visual prosody in text in relation to Flemish Sign Language to see if sign language can be used to explain prosody. We asked deaf readers between 7 and 18 to relate prosodic cues to videos presenting prosodic components of Flemish Sign Language. We found that those readers connect the prosodic cues with the components in Flemish Sign Language as intended. Larger word-spacing correlates with a pause between signs, a wider font with a sign with 'longer duration', a thicker font with more 'displacement' in the sign, a raised font with a 'faster velocity' in the sign. However, some confusion occurred as participants seemed to extract only two prosodic components in the sign language: both the 'faster velocity' and 'longer duration' were referred to in terms of 'speed' and were not perceived as separate prosodic components. Participants were confused about why there were three cues in the text. Therefore, it is advised to re-evaluate and to re-design visual prosody for sign language with only 'displacement' and 'speed' in mind.

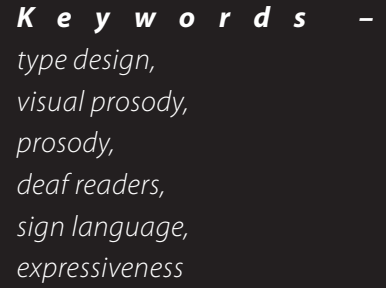




\section{Introduction}

Visual prosody visualizes information that is

otherwise mostly absent in text: information about 'how words are said.'That is the prosody, variations in the loudness, duration, and pitch of the voice. Prosody is the motor of expressive speech and plays an important role in understanding language. It distinguishes words such as PREsent versus preSENT, and it adds additional information: emphasis, statements, questions, sarcasm, emotion, and more. Additionally, it can influence the meaning of a sentence: for example, "That old man CANNOT hear you very well" or "That old man cannot hear YOU very well." Visual prosody adds prosody to text in a visual way using prosodic cues. There exist several different approaches to visual prosody, both for reading a text with more speech variations and for reading comprehension (Renckens et al., 2021; Bessemans et al., 2019; Rude, 2016; Patel \& McNab, 2010).

The perception and production of prosody of deaf readers are not equal to that of their hearing peers (De Clerck et al., 2018; Øydis, 2014; Boons et al., 2013; See et al., 2013; Chin, Bergeson \& Phan, 2013; Vander Beken et al., 2010; Markides, 1983). In our study, 'deaf readers' refers to 'deaf students who have developed spoken language (legible enough to be understood) and Flemish Sign Language in 1) regular education with additional support from a school of the deaf or 2) a signed bilingual educational setting'.

Even high technological digital hearing devices do not provide full access to speech since the perceived sound quality is limited (Dorman et al., 2017; Scarbel, Vilain, Loevenbruck, Schmerber, 2012). Therefore, deaf readers could benefit from visual prosody, which is already applied in teaching materials to exercise vocal variations with deaf readers by several institutions (KIDS, n.d.; Advanced bionics, unpublished; Staum, 1987; van Uden, 1973). For some examples, see Figure 1. Prosodic cues in reading materials help deaf readers aged 7 to 18 to read with more expression and with understanding of the intended meaning of a sentence (Renckens et al., 2021). 
Figure I.a, b \& c.

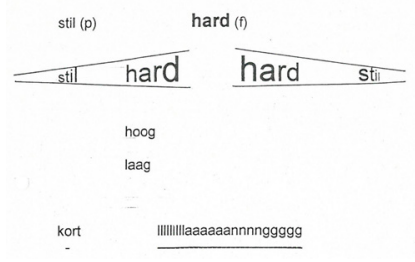

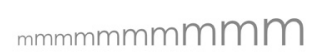

aagaagaaagah

$\mathrm{ma}, \mathrm{ma}, \mathrm{ma}$ oo-bee doo-bee, dooooo

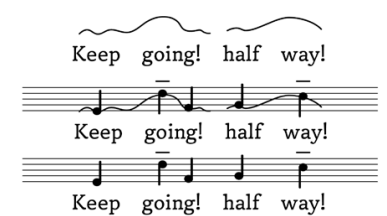

Three examples of visual prosody

in (Dutch) deaf education, all applying similar visualizations: 1. horizontally stretched words (IIIIllaaaaannnngggg, translated as IIlloooonnnnngggg) correlate with a longer duration. 2. bolder and larger text correlates with more loudness, and 3. a higher position, vertically stretched text, a rising line, or music notes correlate with a higher pitch in the voice (left to right: image from KIDS, n.d.; image from Advanced Bionics, unpublished; image based on van Uden, 1973).
Until now, visual prosody was developed with speech properties in mind (loudness, duration, pitch) but not sign language. Because deaf readers often rely not only on spoken language but also on sign language, this study aims to evaluate if visual prosody in text has a consistent relation with (Flemish) sign language. If it has, then sign language could possibly be used to explain/support (speech) prosody for deaf readers in bilingual education.

There are similarities and differences between oral and sign languages. Similar to words in oral languages, signs follow one after another. But unlike in spoken languages, sign language can engage several information sources simultaneously through different body parts and signs require free space surrounding a person to perform a sign (Koenen et al., 2005). Prosody in sign language can be found in two ways: in nonmanual markers and in variations on the signs. First, signs are accompanied by non-manual markers (NMMs), which are all components of sign language that are not formed by the hands (Brentari, Falk \& Wolford, 2015; Elliott \& Jacobs, 2013; Van Herreweghe, 1995). Examples of prosody not made by the hands are the non-manual markers such as mimicry, body posture, shoulder raising, head position, facial expressions, eye blinks, eye shifts, gazes, the position of the lips, and position of the brows. Second, the literature review by Brentari, Falk \& Wolford (2015) pointed to language-independent prosodic components in sign language, made by variations in duration, velocity, and displacement. Those prosodic components are always present, independent 
of how a language applies them, similar as to how pitch, loudness, and duration are always in the voice, regardless of language. It is this second kind of prosody that can be useful for this study: the progress of time is the same for word duration and sign duration in both modalities. The velocity in movement is supposed to resemble frequency in speech, and displacement of movement would correlate with intensity in speech (Brentari, Falk \& Wolford, 2015).

But relating visual prosody to sign language is more difficult than relating it to the voice. Current prosodic cues are designed to be intuitive with the speech in mind. 'Intuitive' means that their intention can be interpreted without much explanation (see also Shaikh, 2009; Lewis and Walker, 1989). For example, 'boldness' correlates to 'loudness' (Shaikh, 2009). But in sign language, the line between syntax and prosody is not yet defined (Sandler, 2010). The prosodic components in sign language are more interwoven with the modality of the language itself: for example, while a signer consciously makes use of hands, face, and body to represent a concept in a sign (van den Bogaerde, 2012), signing the sign 'walking' slowly can mean that the person is walking slow. This interwovenness with the content could influence the intuitive understanding of prosodic cues for sign language.

To evaluate the aim of this research, the hypothesis of this research became "Deaf readers relate typographic prosodic cues designed with the speech properties in mind consistently to prosodic components in Flemish Sign Language."

\section{Methodology}

\section{Prosodic cues}

The existing prosodic cues within the typeface Matilda were used for this study. The relation of these prosodic cues with prosody in speech (according to Bessemans et al., 2019) and the components of sign language (according to the suggestions of Brentari, Falk \& Wolford, 2015) is described in Table 1. 
Figure 2.

A summary of the four prosodic cues used in this study. a thicker font, a wider space, a font raised above the baseline, and a wider font. The sentence is translated as "The big bird flies high."

\section{o De grote vogel vliegt hoog.}

o De grote vogel vliegt hoog.

o De grote vogel vliegt hoog.

o De grote vogel vliegt hoog

\begin{tabular}{|l|l|l|}
\hline $\begin{array}{l}\text { Visual cue in text for this } \\
\text { research }\end{array}$ & $\begin{array}{l}\text { Correlates with prosody in } \\
\text { speech (Bessemans et al, } \\
\text { 2019) }\end{array}$ & $\begin{array}{l}\text { Correlates with prosody in } \\
\text { sign language (Brentari, Falk } \\
\text { \&Wolford, 2015) }\end{array}$ \\
\hline Thicker font & Louder voice & More displacement \\
\hline Larger space & Longer pause & Longer pause \\
\hline Font raised above the baseline & Higher pitch & Faster velocity \\
\hline Wider font & Longer duration & Longer duration \\
\hline
\end{tabular}

Table I.

The suggested relations/similarities between the prosodic cues, the speech variations, and the prosodic components in sign language (based on 1. Bessemans et al., 2019; which is based on earlier studies, and 2. Brentari, Falk \& Wolford, 2015).
This table is not a full summary of prosody: the opposite cues for the opposite direction of each speech variation exist: for example, a softer voice instead of a louder voice. However, a study does not have to include all possible cues to prove the effectiveness of a subset of cues (as in, for example, Patel \& McNab, 2010, Patel, Kember \& Natale, 2014, or Bessemans et al., 2019). To reduce complexity of this test for young readers, these additional cues were not applied in this study.

\section{Video fragments}

Four video fragments were created. In those videos, a 'neutral' sentence in Flemish Sign Language was shown first [Figure 1.A.], followed by the same sentence in Flemish Sign Language but with 
a modulated prosody on the last sign: a "longer pause," "longer duration," "faster velocity" or "more displacement" [Figure 1.B].

Please note that prosody in sign language is much more interwoven with the content of the message than the prosody in speech (e.g., the sign for walking, executed slowly). To avoid such connections, prosody in this research was treated as an independent factor, not connected to the meaning of the message. The effect of prosodic cues on a sign's meaning could become the subject of a follow-up study.

Figure 3.

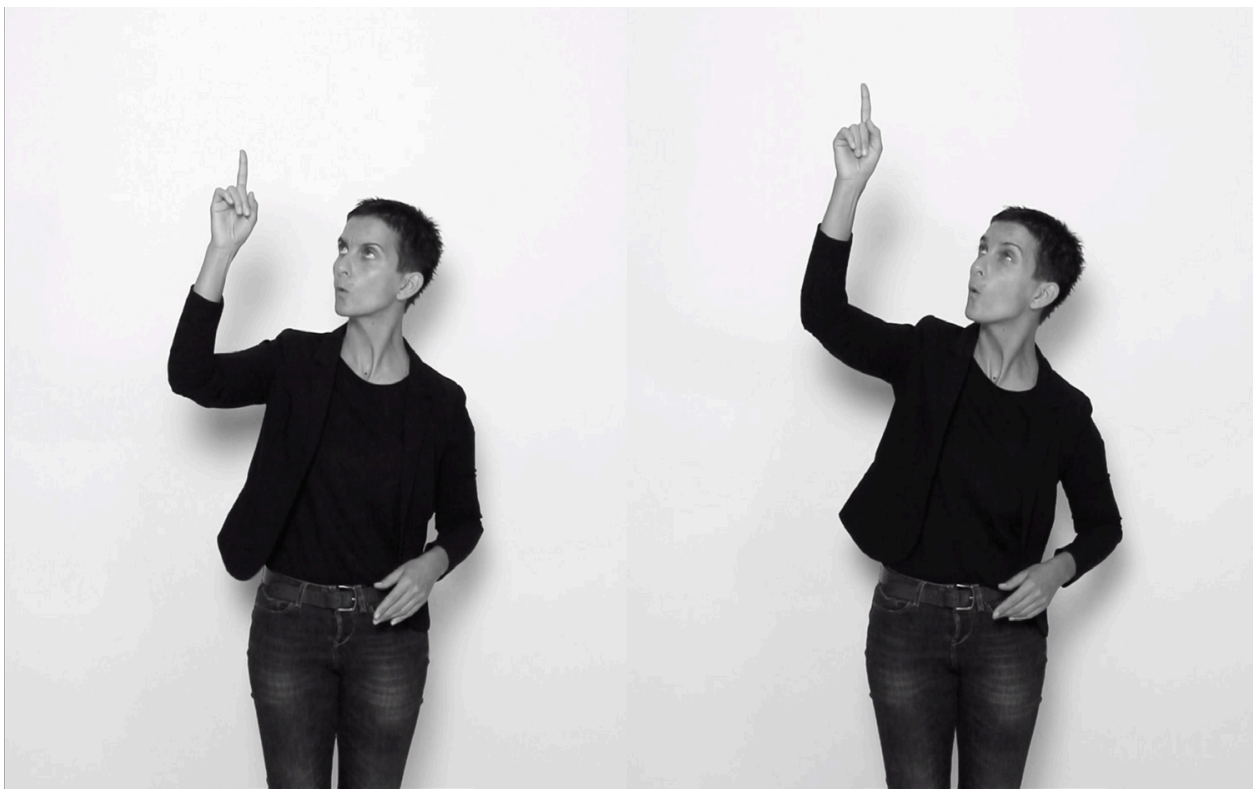

$A$ and $B$. In videos, a signer

performs one recurring sentence

with varying prosodic variations. A:

The neutral sign is shown first. $B$ :

Each neutral sign was followed by a sentence containing one specific variation (e.g., in image B more

displacement than in A) 


\section{Participants}

The cues were tested by 38 deaf readers. In this study, this term refers to readers with hearing remnants who are able to speak. Their native language and preferred language could be either spoken or signed, but all participants were educated 1) regular schools and received additional support from schools of the deaf (often after starting their first education in a school of the deaf), or 2) in a bi-lingual educational environment. They thus had a high chance to come in contact with both spoken and signed languages. All readers were between 7 and 18 years old. The participants' age was evenly spread: for all ages between 7 and 18, each age was represented by at least two participants. These readers followed primary and secondary education in regular schools or schools for the deaf, and most wore one or two hearing devices. Some participants preferred Flemish Sign Language as primary language, and others preferred speech.

Because this research was executed at the same time as the study evaluating visual prosody's influence on the reading aloud (Renckens et al., 2021), the participants enrolled in both research studies at the same time. Therefore, the participants were aware that there was a relationship between the cues and speech prosody but did not yet know which one. Participants were not provided any information about prosody in sign language when this test started.

\section{Procedure}

The participants were asked to look carefully to the video [Figure 3]. Then, they were asked to choose from a list of sentences [Figure 2] the sentence that, according to him/her, corresponded with the last video shown. Participants did not have to know Flemish Sign Language fluently to follow the video fragments. All participants were encouraged to mark an answer. If they were not sure, they could see the video one more time before marking an answer.

This procedure with the videos was repeated: after connecting all movie fragments to written sentences a first time, the movie fragments were shown a second time without the participants knowing that the same videos were shown again. This way, participants watched all prosodic components in Flemish Sign Language twice. The order in which all participants saw the videos was: pause, thicker, extended, higher, pause, extended, higher, thicker.

Participants could provide feedback while answering the question, and the researcher asked questions when a participant was stuck. 


\section{Statistical Analysis}

While relating the cues to the movies, a binomial test with one chance on four to guess correctly, results of 38 persons differ significantly from pure chance $(p<0.05)$ if 14 or more (i.e., $36 \%$ or more) give the same answer.

To see if there was a learning effect and to test if there was a difference between primary and secondary school, proportion tests for two proportions were used.

\section{Results}

\section{Chart I.}

Except for the first time that 'more displacement' was shown (dashed border), prosodic components in Flemish Sign Language were related most of their occurrences to their intended cue (solid border).

\section{Relating cues to the movies}

Except for the first time that 'more displacement' was shown, all cues were related to their intended component in Flemish Sign Language [Chart 1.]. The first time that 'faster displacement' was presented, participants marked the non-intended wider font more often than the intended thicker font [as shown in Figure 1.C] (42\% versus 39\%). All cues were significantly more often related to their intended component in Flemish Sign Language than if participants would have been guessing. No statistically significant learning effects were found between the first and second time a video fragment was shown.

TO WHICH PROSODIC CUES PARTICIPANTS RELATEDTHE PROSODIC COMPONENTS IN THE SIGN LANGUAGE

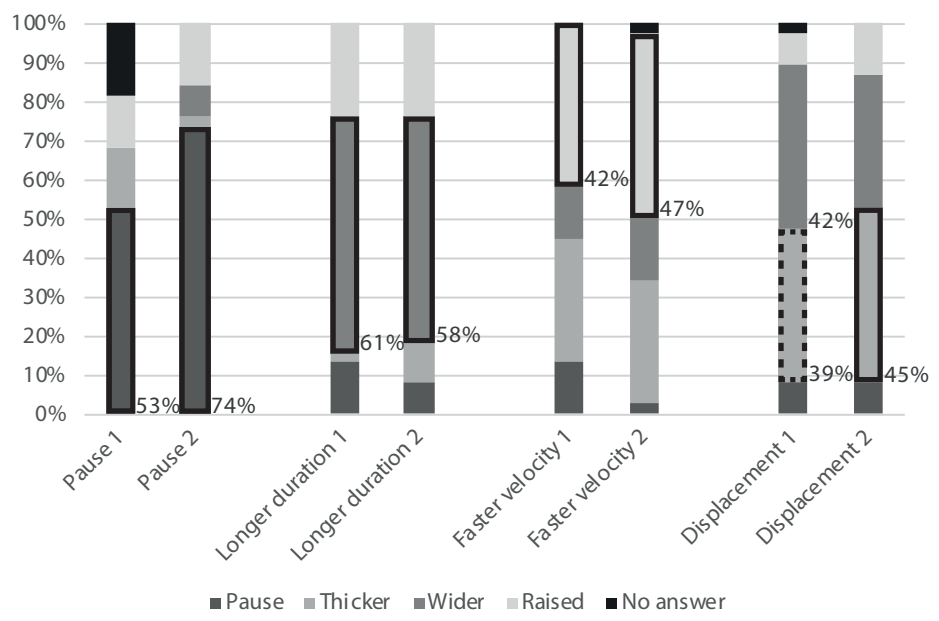




\section{No difference between primary and secondary school}

In total, 22 of the readers took classes in primary school, and 16 of the readers took classes in secondary school. How the participants related the videos with Flemish Sign Language to the intended prosodic cues is stated in Table 2.

Table 2

When participants had to relate videos with prosodic cues, the results varied between $38 \%$ and $77 \%$ correctness.

\begin{tabular}{|c|c|c|c|c|c|c|}
\hline & all (\#) & all (\%) & Primary (\#) & Primary (\%) & Secondary (\#) & Secondary (\%) \\
\hline Pause 1 & 20 & $53 \%$ & 11 & $50 \%$ & 9 & $56 \%$ \\
\hline Displacement 1 & 15 & $39 \%$ & 9 & $41 \%$ & 6 & $38 \%$ \\
\hline Longer duration 1 & 23 & $61 \%$ & 13 & $59 \%$ & 10 & $63 \%$ \\
\hline Faster velocity 1 & 16 & $42 \%$ & 10 & $45 \%$ & 6 & $38 \%$ \\
\hline Pause 2 & 28 & $74 \%$ & 17 & $77 \%$ & 11 & $69 \%$ \\
\hline Displacement 2 & 17 & $45 \%$ & 11 & $50 \%$ & 6 & $38 \%$ \\
\hline Longer duration 2 & 22 & $58 \%$ & 12 & $55 \%$ & 10 & $63 \%$ \\
\hline Faster velocity 2 & 18 & $47 \%$ & 9 & $41 \%$ & 9 & $56 \%$ \\
\hline
\end{tabular}

There was no significant difference between the percentage of correct answers of primary school readers versus secondary school readers for any of the cues presented. It can be argued that this lack of significance is due to the relatively small number of samples. However, notice that in four situations, the students at the secondary school score better, and that in the other four situations, the children of the primary school score better. This favors the idea that there is no age effect.

\section{Some comments of the children during the sessions}

The children's comments were not recorded explicitly, as the children were free to comment on anything that they felt was important. However, two comments kept returning and were deemed important enough to be mentioned here.

First, we noticed that not a single participant used the terms "faster velocity" or "slower duration"; both were described in terms of faster/slower "speed." 
Second, participants deemed the faster velocity more 'difficult' to relate to a font. Four participants explicitly said that they were searching for a prosodic cue that was not in this test but was present in the other tests evaluating speech (such as a narrower font resembling a faster speech, see Renckens et al., 2021). At least six more participants were stuck on this cue, even to that level that the researcher had to intervene and ask what the problem was. The researcher had to tell that, even when they did not see the typeface they were looking for, an answer had to be chosen. Thus, one participant on four was clearly struggling with the cue for a faster velocity.

\section{Discussion}

The cues designed with speech prosody in mind do relate to the intended prosodic components in Flemish Sign Language. A longer pause in sign language correlates with a larger word-space; a sign with a longer duration with a wider font; a sign with more displacement with a thicker font; a sign with a faster velocity correlates with a raised font. These findings are in line with Brentari, Falk \& Wolford (2015)'s review of the similarities between the prosody of speech and sign language (table 1).

We did not find an effect of age. This implies that participants in primary school similarly associated the textual prosodic cues with prosody in Flemish Sign Language as the children in secondary school. This has the advantage that, once the children can read, prosodic cues could be introduced and afterward be used during the whole period they go to school.

\section{But the participants' oral feedback}

exposed confusion when these cues are applied to sign language. The prosodic cues used in this study were designed with three very distinct speech variations in mind: loudness (in decibel), duration (in milliseconds), and pitch (in Hertz). The prosodic components in sign language are very different: displacement (in distance), duration (in milliseconds) and velocity (distance per millisecond). Here, velocity closely resembles duration: both are expressed in 'time'-units (often seconds or milliseconds). This close interwovenness caused confusion for the participants. It seemed that they intuitively only extracted two prosodic components in sign language: displacement and speed. This constitutes the main drawback of this study. We did not anticipate the difficulty the children had with the three prosodic components. We only learned during the data collection that the interwovenness of duration and velocity was exceptionally strong. Because we did not anticipate this issue, we had no alternative prosodic cues to address it.

Despite this confusion, the intended cue for a faster velocity (the raised text) was marked most of the time (42\% and $47 \%$ ). 
That could be explained by the fact that the cue that some participants expected, a narrower font, was not presented (participants knew that cue from the research about the voice that ran at the same time). Participants thus choose a raised font, probably because the bold and wider fonts were already related to another prosodic component in sign language. If more cues would have been provided to choose from, it is uncertain that the task of relating cues to the movies would have been as consequently answered as it was now.

While this study focused on Flemish Sign Language, we can assume that the findings are valid for multiple sign languages, in line with Brentari, Falk, and Wolford (2015), who discussed several sign languages. This should be evaluated with different sign languages and different cultures as a reference, which both could have another perception of prosody.

At this moment, the practical usage of this preliminary study is limited. We evaluated the three prosodic cues most commonly used in visual prosody for speech. The participants' oral feedback pointed out that this approach cannot be transferred to sign language easily. We advise performing a new study that evaluates if two prosodic cues are sufficient to represent the intrinsic characteristics of (Flemish) Sign Language: on one side 'displacement,' on the other side velocity and duration grouped together as 'speed.'

\section{Conclusion}

This research confirms the hypothesis that

"Deaf readers relate typographic prosodic cues designed with the speech properties in mind consistently to prosodic components in Flemish Sign Language." The test was done with participants relating three prosodic cues in type to movies showing prosodic components in sign language. The prosodic cues were correctly related to their intended prosodic component in the sign language.

However, the three prosodic components in sign language are more closely interwoven with each other than the three prosodic speech variations on which the prosodic cues are based. That caused confusion in the terminology used by the readers: "velocity" and "duration" were both referred to as "speed." Thus, readers intuitively extract only two prosodic components in sign language and encounter problems with three prosodic cues in text.

Based on the results of this study, we recommend that visual prosody has to be adapted for sign language. This requires further research. 


\section{Acknowledgments}

We would like to thank all schools in the Dutchspeaking regions that supported this research and facilitated connecting with deaf students. In alphabetical order: Antwerp Plus (Antwerp), BUSO Zonnebos (Schoten), Cor Emous (The Hague), Kasterlinden (Kasterlinden), KIDS (Hasselt), Koninklijk instituut Woluwe (Woluwe), Sint Gregorius (GhentBruges), Sint-Lievenspoort (Ghent), Spermalie (Bruges). Without their help, this research would not have been possible. 


\section{References}

ADVANCED BIONICS. (unpublished version). A musical journey through the rainforest. [Teaching material]

BESSEMANS, A.; RENCKENS, M.; BORMANS, K.; NUYTS, E.; \& LARSON, K. (2019) "Visual prosody supports reading aloud expressively." Visible Language. 53 (3): 28-49.

BOONS, T.; DE RAEVE, L.; LANGEREIS, M.; PEERAER, L.; WOUTERS, J.; VAN WIERINGEN, A. (2013). "Expressive vocabulary, morphology, syntax and narrative skills in profoundly deaf children after early cochlear implantation." Research in Developmental Disabilities. 34: 2008-2022.

BRENTARI, D.; FALK, J.; \& WOLFORD, G. (2015). “The acquisition of prosody in American Sign Language." Linguistic Society of America. 91 (3): e144-e168. https://doi.org/10.1353/lan.2015.0042.

CHIN, S.B.; BERGESON, T.R.; PHAN, J. (2012). "Speech Intelligibility and Prosody Production in Children with Cochlear Implants." Journal of Communication Disorders. 45(5). 355-366. http://dx.doi. org/10.1016/j.jcomdis.2012.05.003.

DE CLERCK, I; PETTINATO, M.; GILLIS, S.; VERHOEVEN, J.; \& GILLIS, S. (2018). "Prosodic modulation in the babble of cochlear implanted and normally hearing infants: a perceptual study using a visual analogue scale." First Language. 38 (5): 481-502. https://doi. org/10.1177/0142723718773957.

DORMAN, M.F.; COOK NATALE, S.; BUTTS, A.M.; ZEITLER, D.M.; \& CARLSON, M.L. (2017). "The sound quality of cochlear implants - Studies with single-sided deaf patients." Otol Neurotol. 38 (8): e268-e273. https://doi:10.1097/MAO.0000000000001449.

ELLIOTT, E.A. \& JACOBS, A.M. (2013). “Facial Expressions, Emotions, and Sign Languages." Frontiers in Psychology. 4 (115) https://doi. org/10.3389/fpsyg.2013.00115.

KIDS (Unpublished). Teaching materials for children with language disorders. [Internal teaching materials].

KOENEN, L.; BLOEM, T.; JANSSEN, R.; \& VAN DE VEN, A. (2005). “Gebarentaal. De taal van doven in Nederland (Sign Language. The language of deaf in the Netherlands)." Vi-Taal: The Hague.

LEWIS, C., \& WALKER, P. (1989). "Typographic influences on reading." British Journal of Psychology. 80, (2), 241-257. 
MARKIDES, A. (1983). The speech of hearing-impaired children. Manchester University Press, New Hampshire, USA.

ØYDIS, H. (2013). Acoustic Features of Speech by Young Cochlear Implant Users. [Dissertation] Universiteit Antwerpen.

PATEL, R., KEMBER, H. \& NATALE, E. (2014). “Feasibility of Augmenting Text with Visual Prosodic Cues to Enhance Oral Reading." Speech Communication. 65. https://doi.org/10.1016/j. specom.2014.07.002

PATEL, R. \& MCNAB, C. (2010). "Feasibility of augmenting text with visual prosodic cues to enhance oral reading." Speech Communication. 53 (3): 431-441.

RENCKENS, M.; DE RAEVE, L.; NUYTS, E.; PEREZ MENA, M.; BESSEMANS, A. (2021). Visual prosody supports reading aloud expressively for deaf readers. Visible Language: 55 (1).

RUDE, M. (2016). Prosodic writing shows $L 2$ learners intonation by $3 d$ letter shapes - state, results, and attempts to increase $3 d$ perception. [Intern document]. University of Nagoya.

SANDLER, W. (2010). "Prosody and syntax in sign languages." Trans Philol Soc: 108(3): 298-328. https://doi. org/10.1111/j.1467-968X.2010.01242.x.

SCARBEL, L.; VILAIN, A.; LOEVENBRUCK, H.; SCHMERBER, S. (2012). "An acoustic study of speech production by French children wearing cochlear implants." 3rd Early Language Acquisition Conference, Dec 2012, Lyon, France.

SEE, R.L.; DRISCOLL, V.D.; GFELLER, K.; KLIETHERMES, S. \& OLESON, J. (2013). "Speech intonation and melodic contour recognition in children with cochlear implants and with normal hearing." Otology and Neurotology. 34 (3): 490-8. https://doi.org/10.1097/ MAO.0b013e318287c985.

SHAIKH, D. (2009). "Know your typefaces! Semantic differential presentation of 40 onscreen typefaces." Usability News. 11, (2).

STAUM, M.J. (1987). "Music Notation to Improve the Speech Prosody of Hearing Impaired Children." Journal of Music Therapy. 24 (3): 146-159.

VAN DEN BOGAERDE, B. (2012). "Kun je alles zeggen in gebarentaal? Over taal van doven en slechthorenden (Can you say anything in sign language? About language of deaf and hard of hearing)." [Online] http://www.taalcanon.nl/vragen/kun-je-alles-zeggen-ingebarentaal. [1 March 2017]. 
VANDER BEKEN, K.; DEVRIENDT, V.; VAN DEN WEYNGAERD, R.; DE RAEVE, L.; LIPPENS, K.; BOGAERTS, J.; MOERMAN, D. (2010). “Personen met een auditieve handicap (Persons with an auditory handicap)." In: BROEKAERT et al. (2016: fourteenth press) Handboek bijzondere orthopedagogiek (Manual for extraordinary remedial education). Garant. Antwerpen-Apeldoorn. p 131-210.

VAN HERREWEGHE, M. (1995). De Vlaams-Belgische gebarentaal: een eerste verkenning (The Flemish-Belgian Sign Language: a first exploration). Ghent: Academia Press.

VAN UDEN, A. (1973). Taalverwerving door taalarme kinderen (Language acquisition by language-poor children). Universitaire Pers Rotterdam, Rotterdam. 


\section{Authors}

\section{Maarten Renckens}

Maarten Renckens is a teacher and design researcher with a love for letters and a heart for people. Dealing with a reading difficulty himself, he is very interested in the reading process. His projects include the typeface 'Schrijfmethode Bosch' (Writing Method Bosch) that learns children how to write and typefaces to encourage beginner readers and readers with hearing loss to read more expressively. With a background in architectural engineering, he is used to approach concepts technically and mathematically. He applies this technical knowledge to unravel letterforms, in order to determine the effects of different letterforms on the reading process.

\section{Leo De Raeve}

Leo De Raeve PhD has 3 professions: he is a Doctor in Medical Sciences, psychologist and teacher of the deaf. He is founding director of $\mathrm{ONICl}$, the Independent Information and Research Center on Cochlear Implants, is lecturer at University College Leuven-Limburg and scientific advisor of the European Users Association of Cochlear Implant (EURO-CIU).

\section{Erik Nuyts}

Prof. Dr. Erik Nuyts is researcher and lecturer at the University College PXL and associate professor at the University of Hasselt. He got a master degree in mathematics, and afterwards a PhD in biology.

Since his specialty is research methodology and analysis, his working area is not limited to one specific field. His experiences in research, therefore, vary from mathematics to biology, traffic engineering and credit risks, health, physical education, (interior) architecture and typography.

His responsibilities both at the University College PXL as at the University of Hasselt involve preparation of research methodology, data collection and statistical analyses in many different projects. He is responsible for courses in research design, statistics, and mathematics. 


\section{María Pérez Mena}

Dr. María Pérez Mena is an award-winning graphic and type designer. She is postdoctoral researcher at the legibility research group READSEARCH at PXLMAD School of Arts and Hasselt University. María teaches typography and type design in the BA in Graphic Design at PXL-MAD and is lecturer in the International Master program 'Reading Type \& Typography' and the Master program 'Graphic Design' at the same institution. She received her PhD "with the highest distinction" from University of Basque Country and is a member of the Data Science Institute UHasselt.

\section{Ann Bessemans}

Prof. Dr. Ann Bessemans is a legibility expert and award-winning graphic and type designer. She founded the READSEARCH legibility research group at the PXL-MAD School of Arts and Hasselt University where she teaches typography and type design. Ann is the program director of the international Master program 'Reading Type \& Typography'. Ann received her PhD from Leiden University and Hasselt University under the supervision of Prof. Dr. Gerard Unger. She is a member of the Data Science Institute UHasselt, the Young Academy of Belgium and lecturer at the Plantin Institute of Typography. 